\title{
Development, Characterization, and Stability of O/W Pepper Nanoemulsions Produced by High-Pressure Homogenization
}

\author{
K. C. S. Galvão ${ }^{1}$ - A. A. Vicente ${ }^{2}$ P. J. A. Sobral ${ }^{1}$
}

Received: 23 April 2017 / Accepted: 19 October 2017 / Published online: 15 November 2017

(C) Springer Science+Business Media, LLC 2017

\begin{abstract}
Interest in the utilization of bioactive plant compounds in foods has increased due to their biochemical activities (antioxidant, antimicrobial, etc.), and as alternatives in the reduction of the use of high concentrations of chemical substances. However, some of these additives are hydrophobic, thus being harder to disperse into the food matrix, which is generally water-based. A good alternative is the use of low concentrations of these compounds as nanoemulsions. The objective of the present study was to develop oil-in-water nanoemulsions containing "dedo-de-moça" pepper extract for food applications. Research in the development of these nanoemulsions was carried out using a high-speed homogenizer, followed by a high-pressure homogenizer. The influence of the following parameters was assessed: type and concentration of surfactants, hidrophilic-lipophilic balance, lipid/ aqueous phase ratio, surfactant/oil ratio, pepper extract composition in nanoemulsion, and processing conditions. Nanoemulsions were evaluated by environmental (centrifugal and thermal) and storage stabilities, characterized by average
\end{abstract}

Chemical compounds evaluated in this article

Tween 80 (PubChem CID: 5281955); Span 80 (PubChem CID: 347521).

K. C. S. Galvão

karencristine13@gmail.com

A. A. Vicente

avicente@deb.uminho.pt

P. J. A. Sobral

pjsobral@usp.br

1 School of Animal Science and Food Engineering, University of São Paulo, Duque de Caxias Norte, 225, Pirassununga 13635-900, Brazil

2 IBB-Institute for Biotechnology and Bioengineering, Centre of Biological Engineering, University of Minho, Gualtar Campus, 4710-057 Braga, Portugal droplet size and $\zeta$-potential measurements, color, interfacial tension, atomic force, and cryo-scanning electron microscopy. Those with average droplet size between $132 \pm 2.0$ and $145 \pm 1.0 \mathrm{~nm}$ were developed depending on working pressure and number of cycles; $\zeta$-potential was around $-36.71 \pm 0.62 \mathrm{mV}$ and the best nanoemulsion was stable to centrifugation and most of the thermal stresses. Droplets were characterized with cryo-scanning electron microscopy as being spherical, homogeneous, and stable, and remained stable when stored at $4{ }^{\circ} \mathrm{C}$ and room temperature for over 120 days. The pepper nanoemulsion, developed in the present study, has potential applications in the food industry.

Keywords Colloidal systems · Capsicum spp. · Emulsion · Electron microscopy $\cdot$ AFM

\section{Introduction}

The interest in safe, contaminant-free, and healthier food is currently increasing in the international market. In this context, food industries need to adapt, seeking technological innovations that meet the production of food with longer shelf life, due to resistance to oxidation and maintenance of food free of microbial contamination. Additionally, consumers consider that minimally processed foods, which are free of chemical additives, are a better buying option (Ernandes and Garcia-Cruz 2007). As economic and technological alternatives, there is a deep interest in finding in plants, especially in spices, active ingredients that have antioxidant and antimicrobial activity, and that may contribute to the conservation of food, produced with safety to humans and the environment (Costa et al. 2009; Sricharoen et al. 2016).

The use of active plant ingredients (essential oils, plant extracts, or fractions) is interesting due to a large number of 
biochemical activities (Martillanes et al. 2017) and can be interesting to the food industries which need to change the traditional processes because of consumers' preoccupation. Meat industry is already searching alternatives to reduce or replace some substances, as nitrite (Hung et al. 2016). Spices such as red peppers, especially Capsicum ssp., also known as the Brazilian "dedo-de-moça" pepper, were widely used in food in ancient civilizations and are sources of several antioxidant compounds (Costa et al. 2009). In general, peppers are rich in antioxidant compounds, including capsaicin, which can contribute to the prevention of diseases caused by the oxidative stress of human cells, such as cancer, atherosclerosis, and other degenerative diseases (Silva et al. 2009; Sricharoen et al. 2016). The main principle in peppers is capsaicin, responsible by pungency. It is a colorless and odorless lipophilic alkaloid. This characteristic can be useful to extract capsaicin using natural vegetable oils maintaining its original characteristics (Reyes-Escogido et al. 2011). The capsaicin molecule is pointed as a lose weight helper, it is hypocholesterolemic, and has been extensively studied due to its antimicrobial activities (Xing et al. 2006), specially against bacteria (Wei et al. 2006), what is really interesting for food industries that needs to change traditional chemical preservatives by natural ones.

The incorporation of these natural compounds in the food matrix or active packaging is remarkable; however, some of them are hydrophobic, being, therefore, difficult to disperse in food formulation, which is generally water-based. An innovative and new alternative is the use of hydrophobic compounds with efficient biological activities as the dispersed phase of nanoemulsions, allowing better dissolution of active ingredients into the food matrix, and controlled release (Weiss et al. 2006). Nanoscience and nanotechnology are progressing by the day with the increment of advances, enabling innovations in food industries. Currently, the primary field in food production is the design and development of new functional food ingredients that are stable to thermal processes and show high water solubility, bioavailability, and good sensory quality, in addition to retaining high physiological performance (Shantilal and Bhattacharya 2014).

Nanoemulsions can be described as kinetically stable conventional emulsions containing very small spherical droplets at the nanometer level (Anton and Vandamme 2011; Klang et al. 2012; Mason et al. 2006; McClements 2012; Rao and McClements 2012; Silva et al. 2012; Sivakumar et al. 2014). Nanoemulsions can be prepared by high or low energy methods. The high energy technique can be scaled for industries and is based on the use of equipment capable of generating high-intensity forces that break up dispersed phase droplets, leading to the formation of nanosize droplets. Several devices, such as high-shear homogenizers, high-pressure homogenizers, high-pressure microfluidizers, evaporators, or ultrasound generator may be used to generate these forces
(Anarjan et al. 2010; Cheong et al. 2008; Huang et al. 2009; Kentish et al. 2008; Lee and McClements 2010; Silva et al. 2011; Weiss et al. 2006).

Studies about the influence of processing conditions, including evaporation temperature, number of cycles, and working pressure on the physico-chemical properties of astaxanthin nanoemulsions produced with a combined technique involving homogenization and evaporation have demonstrated that alterations of processing conditions causes a great impact in final emulsion characteristics (Anarjan et al. 2010). Also, it has been demonstrated that surfactants are also important to reach a stable emulsion. Choi et al. (2009) worked with Tween ${ }^{\circledR} 20,40,60$, and 80 , sucrose mono-stearate, and polypropylene glycol to prepare capsaicin nanoemulsification and observed that the best ones were obtained using Tween ${ }^{8} 80$.

High-pressure systems can be classified based on the geometry and design of the nozzle and flow orientation. It can be also classified by the type of construction (nozzle is decisive for the efficiency in the rupture of the drops with the use of equipment), which can be sub-divided into radial diffusers (standard), jet dispersers, microfluidizers, and orifice valves. For industrial scale, often it is generate radial flow as the primary emulsion passes through the valve, undergoes a mixture of shear, cavitation, and turbulent flow and the working pressure is determined by the force acting between the nozzle and the resulting gap (Jafari et al. 2008).

The objective of this study was to investigate the effect of different preparation conditions on droplet size and droplet distribution of a pepper extract $\mathrm{O} / \mathrm{W}$ nanoemulsion and, also, to investigate its environmental and storage stabilities. The conditions tested were as follows: time versus pressure at high-pressure homogenization, and composition (oil phase, aqueous phase, and emulsifier concentrations).

\section{Material and Methods}

Experiments were carried out at Laboratory of Food Technology (Faculty of Food Engineering and Animal Sciences, University of São Paulo-Brazil) and at Laboratory of Industry and Process (Centre of Biological Engineering, University of Minho-Portugal).

\section{Materials}

The "dedo-de-moça" pepper $(1 \mathrm{~kg})$ and soybean oil $(1 \mathrm{~L}$, Liza, Cargill, Brazil) were bought from a local market, and the oil was employed without any purification. The surfactants (Tween ${ }^{\circledR} 20,40,60$, and 80; and $\operatorname{Span}{ }^{\circledR} 20,40,60$, and 80) were purchased from Sigma-Aldrich Co. (St. Louis, MO, USA), and Milli-Q® water was obtained from a Milli-Q® Integral Water Purification System (Merck Millipore Co., Darmstadt, Germany). 


\section{Production of "dedo-de-moça" Pepper Extract}

"Dedo-de-moça" pepper was dried in an oven (Fanem, Brazil), at $60{ }^{\circ} \mathrm{C}$ during $24 \mathrm{~h}$. Next, the spice was ground and dispersed $(6 \% \mathrm{w} / \mathrm{v})$ in commercial soybean oil at $85^{\circ} \mathrm{C}$ under stirring for $1.5 \mathrm{~h}$. The dispersion was subsequently maintained under refrigeration $\left(4{ }^{\circ} \mathrm{C}\right)$ in amber glass for 3 months to extract lipophilic compounds.

\section{Primary Emulsion Preparation}

Oil-in-water $(\mathrm{O} / \mathrm{W})$ coarse emulsions were prepared by homogenizing a mixture of the lipid phase (soybean oil), the aqueous phase (Milli-Q ${ }^{\circledR}$ water), and surfactants (Tween ${ }^{\circledR}$ 80 and Span ${ }^{\circledR} 80$ ), using a high-speed homogenizer (UltraTurrax, T-25, IKA, Staufen, Germany); aqueous phase containing Tween ${ }^{\circledR} 80$ and lipid phase containing Span ${ }^{\circledR} 80$ were heated, separately, in a water bath at $40{ }^{\circ} \mathrm{C}$ for $30 \mathrm{~min}$, and then, homogenized. Several process conditions were analyzed (Fig. 1), such as the following: (a) homogenization speed (from 7000 to $25,000 \mathrm{rpm}$ ) and time (from 1 to $34 \mathrm{~min}$.), and an increasing gradient of speed (7000, 12,000, 16,000, 20,000, and 25,000 rpm; 1 min at each speed); (b) oil (from 2 to $20 \% w / w$ emulsion) and surfactant (from 1 to $5 \% w / w$ oil phase) concentrations; and (c) influence of hidrophiliclipophilic balance (HLB) according to Prista et al. (1992). Optimal conditions were established based on droplet size and size distribution and then, an emulsion was prepared utilizing pepper extract as the oil phase.

Furthermore, the influence of the order of the mixed phases was studied using four different approaches (Gullapali and Sheth 1999): A - the aqueous phase, containing a blend of hydrophilic and lipophilic surfactants, was poured under the oil phase; B - the oil phase, with a mixture of surfactants, was poured under the aqueous phase; $\mathrm{C}$ - the aqueous phase, containing the hydrophilic surfactant, was poured under the oil phase containing the lipophilic surfactant; and D-the oil phase, with the lipophilic surfactant, was poured under the aqueous phase containing the hydrophilic surfactant.

\section{Nanoemulsion Preparation}

Nanoemulsions were prepared by placing the coarse emulsion in a high-pressure homogenizer (Nozzle Z5, Nano DeBEE, Bee International, USA). The device was covered with ice bags to avoid high temperature caused by high-shear forces. A total of $50 \mathrm{~mL}$ of the coarse emulsion was subjected to the homogenizer, using different cycles (5 to 20 ) under different homogenization pressures $\left(6.9 \times 10^{7}\right.$ to $\left.13.8 \times 10^{7} \mathrm{~Pa}\right)$. In order to avoid mixture of no-homogenized and homogenized sample or any interferences, $20 \mathrm{~mL}$ were discarded after each process.

\section{Interfacial Tension of Raw Material}

Interfacial tension between oil and aqueous phases for a composition equal to $2: 1: 97 \% \mathrm{w} / \mathrm{w}$ (oil, surfactants, and water, respectively) were determined using the DU Noüy ring method and a balance tensiometer, at $25^{\circ} \mathrm{C}$, according to Persson et al. (2014). The density of the aqueous phase (Milli-Q ${ }^{\circledR}$ water plus Tween ${ }^{\circledR} 80$ ) and the oil phase (pepper extract plus Span ${ }^{\circledR} 80$ ) were previously measured using a densitometer (DMA 4500, Anton Paar, UK).

\section{Characterization of Pepper Nanoemulsions}

The nanoemulsions produced in all of the experiments were characterized regarding the determination of average droplet size, polydispersity, and $\zeta$-potential.

The pepper extract nanoemulsion prepared under optimal conditions (smaller droplet size, size distribution, and $\zeta$ potential) was also characterized by atomic force microscopy (AFM), cryo-scanning electron microscopy (CSEM), and color determination. Nanoemulsion stability was also assessed, based on environmental stress and different storage temperatures during 120 days.

\section{Average Droplet Size, Polydispersity, and $\zeta$-Potential Measurements}

The droplet size and size distribution (polydispersity index) and $\zeta$-potential of the nanoemulsions were measured by dynamic light scattering (DLS) (Zetasizer NanoZS laser diffractometer, Malvern Instruments Ltd., Worcestershire, UK) at $25^{\circ} \mathrm{C}$. Intensity-weighted average droplet diameters were described as "Z-average" and measurements were carried out at $633 \mathrm{~nm}$ and a fixed angle of $90^{\circ}$ with acrilic cuvettes. The $\zeta$ potential of the droplets was measured by phase-analysis light scattering with an acrilic electrode, and the polydispersity index was characterized by distribution curves in intensity (\%). For these analyses, the nanoemulsions were previously diluted (1:1000) in ultrapure water to avoid multiple scattering.

\section{Atomic Force Microscopy}

The optimal pepper extract nanoemulsion was analyzed by atomic force microscopy (AFM) to characterize droplet shape and surface morphology. The nanoemulsion was diluted in ultrapure water (1:10), and $\mathrm{a} \sim 15 \mu \mathrm{L}$ droplet was placed onto a cover glass and kept at room temperature for $24 \mathrm{~h}$ for sample surface adsorption. Adsorbed samples were observed in peak force tapping mode, using an AFM device (Nanoscope III controller, Bruker, Germany) with NCHV tips. 
Fig. 1 Fluxogram of tests for nanoemulsion preparations

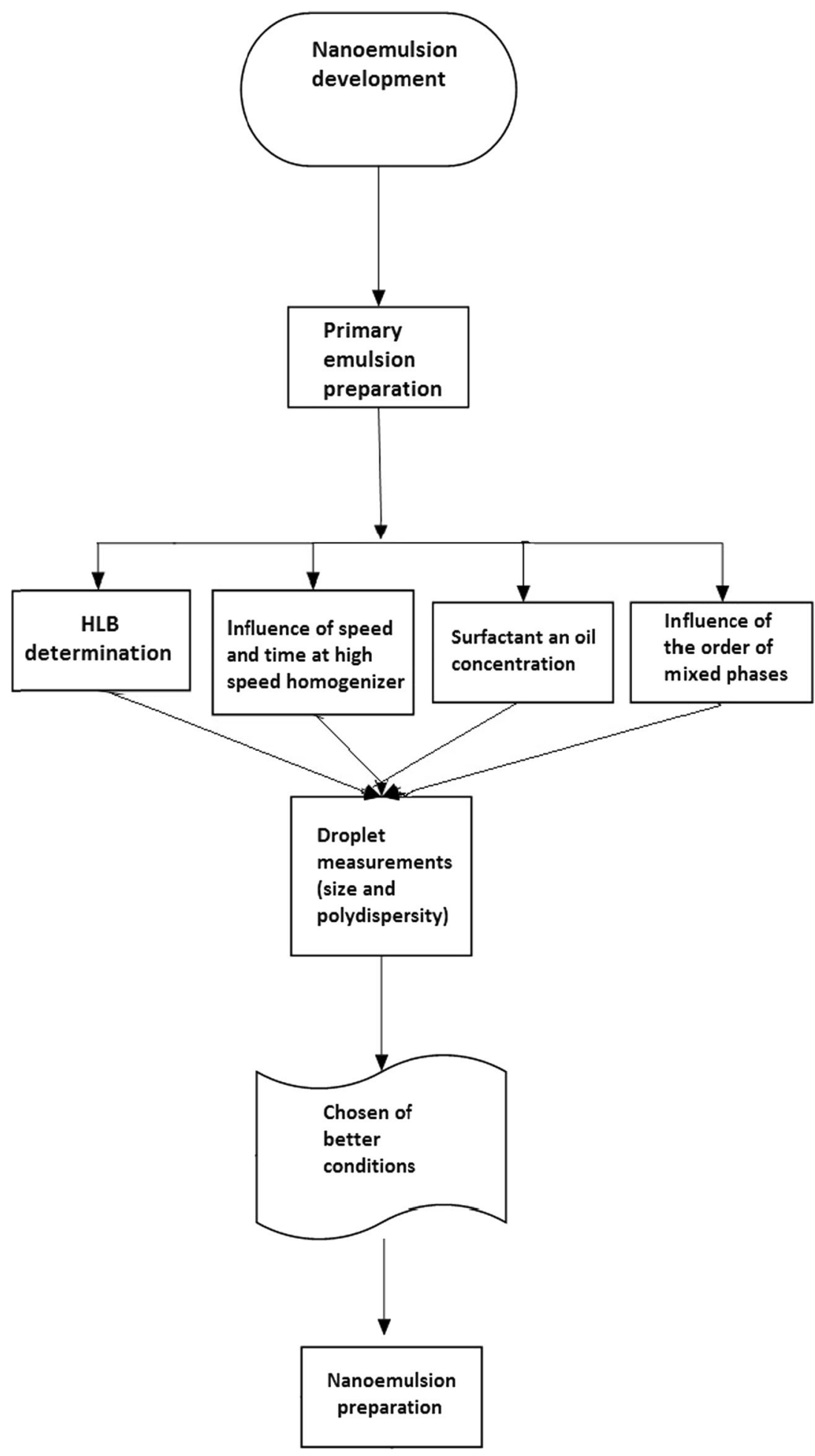

\section{Cryo-scanning Electron Microscopy}

Cryo-scanning electron microscopy (CSEM) was carried out as a complementary tool for droplet size and morphology characterization. The undiluted optimum pepper extract nanoemulsion was placed into carbon-coated grids and immersed in $\mathrm{N}_{2}$ for $30 \mathrm{~s}$. Next, it was transferred, under vacuum conditions, to a preparation chamber (Gatan Alto 2500, UK). Aliquots of the sample were fractured and sublimated at $-90{ }^{\circ} \mathrm{C}$ during $3 \mathrm{~min}$, and coated by ionic pulverization with $\mathrm{Au} / \mathrm{Pd}$ under $12 \mathrm{~mA}$ during $40 \mathrm{~s}$. CSEM images were recorded at $-150{ }^{\circ} \mathrm{C}$ using a scanning electron microscope (JEOL JSM 
6301F/ Oxford INCA Energy 350, Japan), with X-ray microanalyses and an observation system, at low temperature.

\section{Color}

The color of the optimal pepper extract nanoemulsion was characterized using a CIELab system with a portable colorimeter (Minolta CR-400, Konica Minolta Sensing, Inc., Osaka, Japan), set up with a D65 illuminant, and calibrated with a standard white plate, at room temperature. The $\mathrm{L}^{*}, \mathrm{a}^{*}$, and $\mathrm{b}^{*}$ variables were determined, and the whiteness index (WI) of the nanoemulsion was calculated using Eq. 1 (Salvia-Trujillo et al. 2013; Vargas et al. 2008):

$W I=100-\left(\left(100-L^{*}\right)^{2}+\left(a^{* 2}+b^{* 2}\right)\right)^{0.5}$

In which $W I=$ whiteness index, $L^{*}=$ lightness $; a^{*}=$ green $/$ red axis, and $b^{*}=$ blue/yellow axis.

\section{Environmental Stability of the Pepper Extract Nanoemulsion}

Stability of the optimum pepper extract nanoemulsion was evaluated by centrifugal stress, thermal stress, and freezethaw cycling stress. In all the assays, the responses were based on visual observations and average droplet size, polydispersity, and $\zeta$-potential, determined as described in the "Average Droplet Size, Polydispersity, and $\zeta$-Potential Measurements" section.

\section{Centrifugal Stress}

Conical Eppendorf tubes containing $2 \mathrm{~mL}$ of the sample were subjected to different speeds $(80-3050 \mathrm{~g}$ ) in a centrifuge (rotor $7.1 \mathrm{~cm}$, Mikro 120, Hettich, UK) during $15 \mathrm{~min}$, subsequently cooled at room temperature for $30 \mathrm{~min}$, gently mixed and analyzed.

\section{Thermal Processing Stability}

Water bath heating stability was evaluated according to Yang and McClements (2013). Conical Eppendorf tubes containing $2 \mathrm{~mL}$ of the nanoemulsion were incubated in a water bath at 70 and $90{ }^{\circ} \mathrm{C}$ for $30 \mathrm{~min}$. The samples were subsequently cooled at room temperature for $30 \mathrm{~min}$, gently mixed and analyzed. Analyses of these samples were performed after $24 \mathrm{~h}$ and 7 days.

Heating/Cooling Cycling Stability Additionally, thermal cycling stability was performed according to Saranya et al. (2012), with some modifications. Conical Eppendorf tubes containing $2 \mathrm{~mL}$ of the nanoemulsion were submitted to 6 cycles of cooling at $4{ }^{\circ} \mathrm{C}$ for $24 \mathrm{~h}$, followed by heating at $45^{\circ} \mathrm{C}$ for $24 \mathrm{~h}$. Samples were gently mixed and analyzed after each cycle.

Temperature Ramp (Temperature Gradient) A gradient of temperature was performed using a cooling/heating thermostat (CH-100, Cooling and Heating Thermostat, Biosan, EU). Conical Eppendorf tubes containing $2 \mathrm{~mL}$ of the nanoemulsion were cooled to $-10{ }^{\circ} \mathrm{C}$, after which the temperature was quickly raised in -10 until $80^{\circ} \mathrm{C}$, every $30 \mathrm{~min}$.

Freeze-Thaw Cycling Stability Freeze-thaw cycling stability was determined according to Aoki et al. (2005) and Mun et al. (2013). Conical Eppendorf tubes containing $2 \mathrm{~mL}$ of the nanoemulsion were submitted to freezing and thawing cycles by incubating the samples in a freezer at $-22{ }^{\circ} \mathrm{C}$ for $22 \mathrm{~h}$, followed by thawing by incubation of the conical Eppendorf tubes in a water bath at $30^{\circ} \mathrm{C}$ for $2 \mathrm{~h}$. Cycles were repeated six times, or until visual phase separation or creaming occurred.

\section{Storage Stability}

Tubes containing $2 \mathrm{~mL}$ of the nanoemulsion were stored at 4 , 25 , and $37^{\circ} \mathrm{C}$. At $7,15,30,60,90$, and 120 days of storage, an aliquot of each sample was gently mixed and a portion of the center was taken and analyzed immediately for the parameters as mentioned in the "Environmental Stability of the Pepper Extract Nanoemulsion” section.

\section{Statistical Analyses}

Data were statistically analyzed using one-way analysis of variance with significance level set at 0.5 . When a significant difference was detected, Tukey test was performed for mean comparison. All the analyses were performed in triplicate, using a Minitab (Minitab 15 software package, State College, USA).

\section{Results and Discussion}

\section{HLB Value}

Surfactant affinity for aqueous or oil phases is crucial in the production of $\mathrm{O} / \mathrm{W}$ or $\mathrm{W} / \mathrm{O}$ emulsions. According to preliminary experiments (all Tween and Span families were tested in emulsions containing 85:15:5\% $w / w$ of aqueous phase, lipid phase and surfactant concentrations, respectively, and observed after $24 \mathrm{~h}$ for coalescence or visual phase separation), regarding pepper extract emulsions, the HLB value in which a visually stable emulsion was produced was 6.7 for soybean oil emulsions and needed to be adjusted to 6.9 by using pepper 
extract as oil phase; this shows little chemical changes that could impact the droplet size and its stability. Different combinations of Tween $(20,40,60$, and 80$)$ and Span $(20,40,60$, and 80 ) were tested, but just when the mixture of Tween 80 and Span 80 was used, an emulsion, with no separated phases, was obtained. Schmidts et al. (2009) reported affinity between the mixture of Tween ${ }^{\circledR} 80$ and Span ${ }^{\circledR} 80$ and vegetable oils, and stated that both are long chain fatty acids with unsaturated bonds, which facilitate emulsion formation, corroborating with the formation of stable $\mathrm{O} / \mathrm{W}$ emulsions.

\section{Characterization of Raw Material—Interfacial Tension}

Interfacial tension is related to the influence of Laplace pressure, in which low values facilitate the breakage of droplets, generating small average droplet sizes and higher stability against coalescence (Nazarzadeh et al. 2013). The interfacial tension between oil phase $\left(0.75 \%\right.$ Span ${ }^{\circledR}$ plus $2 \%$ pepper extract $-w / w)$ and aqueous phase $\left(0.25 \%\right.$ Tween ${ }^{\circledR} 80$ plus $97 \%$ Milli-Q water $-w / w$ ) was $39.3 \pm 0.01 \mathrm{mN} / \mathrm{m}$. This result was similar to that determined by Matsaridou et al. (2012), who, despite the fact of working with different surfactants (Cremophor(®) EL and Cremophor(®) RH 40) in oil/water emulsions, described interfacial tensions varying between 41 and $45 \mathrm{mN} / \mathrm{m}$. Low values of interfacial tension are suggested to facilitate the nanodroplet formation.

\section{Influence of Processing Parameters on Soybean Oil Coarse Emulsion}

\section{Effect of Homogenization Speed and Time}

All studied combinations of speed and time using a highspeed homogenizer produced coarse emulsions with average droplet size larger than $1000 \mathrm{~nm}$. Initially, it was chosen the same time for all tested speed ( $5 \mathrm{~min}$ ), but it was observed that the emulsion turned to gray and destabilized (Table 1). But, when homogenization speed was increased (7000 rpm $\rightarrow$ $12,000 \mathrm{rpm} \rightarrow 16,000 \mathrm{rpm} \rightarrow 20,000 \mathrm{rpm} \rightarrow 25,000 \mathrm{rpm}$ ), during $1 \mathrm{~min}$ at each speed, the produced coarse emulsion had an average droplet size smaller than $300 \mathrm{~nm}$; thus, the combination of time and gradual increase of speed had the better droplet size and visual stability. Although the high-speed homogenization is just a pre-processing operation, it may reduce the average droplet size and increase the number of droplets more uniformly (Guojun et al. 2014).

\section{Influence of the Order of Phase Mixing}

The order of mixing was studied for emulsions formed by $85: 15: 5 \% w / w$ of aqueous phase, lipid phase, and surfactant, respectively. Intense foaming and incomplete dissolution were observed when the coarse emulsions were prepared with the aqueous phase and the blend of hydrophilic and lipophilic surfactants, poured under the oil phase; or with the oil phase and the mixture of surfactants, poured under the aqueous phase. Moreover, a homogeneous and turbid emulsion, without foam, was produced when the aqueous phase, with the hydrophilic surfactant, was poured under the oil phase, containing the lipophilic surfactant; however, it destabilized after a few hours. A more visual stable emulsion (no creaming nor phase separation) was produced only when the oil phase, with the lipophilic surfactant, was poured under the aqueous phase, containing the hydrophilic surfactant.

These observed results corroborated with those described by Takamura et al. (1979), which demonstrated that emulsion homogenization was best obtained when Tween ${ }^{\circledR}$ was dissolved in the aqueous phase and Span ${ }^{\circledR}$ in the oil phase. According to these authors, the mentioned behavior occurred because Tween ${ }^{\circledR}$ has an affinity for water, needing to be hydrated for some hours before the homogenization process; Span ${ }^{\circledR}$, on the other hand, has an affinity for oil phases.

\section{Effect of Oil and Surfactant Concentrations}

Smaller droplets $(213 \mathrm{~nm})$ with optimum size distribution (poly-dispersion index $(\mathrm{PDI})<0.2$ ) were obtained when concentrations of soybean oil, surfactants, and Milli- ${ }^{\circledR}$ water were $2.5: 2.5: 95 \% \mathrm{w} / \mathrm{w}$ (Table 2). These results probably occurred due to sufficient concentrations of the surfactant, which were enough to fully cover the newly formed droplets of oil and rapidly adsorb at the interface (Matsaridou et al. 2012). Other studies suggested that oil/ surfactant (surfactant families similar as used in this work) ratios of $1: 1$ or $2: 1$ tend to be ideal (Bernardi et al. 2011; Qian and McClements 2011), and, despite the fact that equal concentrations of oil and surfactants result in lower droplet sizes, it is interesting to use minimal possible surfactant concentrations $(\sim 1 \%)$, in order to avoid foam formation. Excess of foam may lead to the formation of micelles, which may aggregate and result in Ostwald ripening.

The best formulation was chosen based on minimum surfactant concentration and was re-done using pepper extract as the oil phase, with an adjustment of 2:1:97\% w/w (oil, surfactants, and water, respectively). As a result, average droplet sizes of $272 \pm 4.0 \mathrm{~nm}$, polydispersity index of $0.277 \pm 0.004$, and $\zeta$-potential of $-36.71 \pm 0.62 \mathrm{mV}$ were observed. These values can be considered satisfactory, since polydispersity index lower the 0.3 (Bernardi et al. 2011) and $\zeta$-potential more negative than $-30 \mathrm{mV}$ are ideals to maintain emulsion stability (Hsu and Nacu 2003); therefore, an average droplet size lower than $300 \mathrm{~nm}$ can possibility the use of lower energy at next steps of reduction droplet size. 
Table 1 Effect of homogenization speed and time on average droplet size and polydispersity of soybean oil coarse emulsions $(97: 2: 1 \% w / w$ of aqueous phase, lipid phase, and surfactant concentrations, respectively) produced by high-speed homogenization

\begin{tabular}{llll}
\hline Speed (rpm) & Time (min) & Average droplet size (nm) & Polydispersity \\
\hline 12,000 & 5 & $1547 \pm 95^{\mathrm{ab}}$ & $0.350 \pm 0.008^{\mathrm{B}}$ \\
16,000 & 5 & $1265 \pm 117^{\mathrm{b}}$ & $0.416 \pm 0.090^{\mathrm{AB}}$ \\
20,000 & 3.5 & $1783 \pm 215^{\mathrm{a}}$ & $0.452 \pm 0.025^{\mathrm{A}}$ \\
25,000 & 1 & $1351 \pm 40^{\mathrm{ab}}$ & $0.391 \pm 0.025^{\mathrm{AB}}$ \\
$7000+12,000+16,000+20,000+25,000$ & $1+1+1+1+1$ & $270 \pm 4$ to $295 \pm 7^{\mathrm{c}}$ & 0.210 to $0.270^{\mathrm{C}}$ \\
\hline
\end{tabular}

Equal letters indicate no significant difference $(p>0.05)$ between samples in the same column

\section{Production of Pepper Extract Nanoemulsions: Effect of Pressure and Number of Cycles Using a High-Pressure Homogenizer}

Smallest average droplet sizes of pepper extract nanoemulsions were obtained at $10.3 \times 10^{7} \mathrm{~Pa}$ undergoing $5(132 \mathrm{~nm})$ and 10 cycles $(134 \mathrm{~nm})$, and at $13.8 \times 10^{7} \mathrm{~Pa}$, with 5 cycles $(132 \mathrm{~nm})$ (Table 3). However, all samples showed PDI lower than 0.15 and $\zeta$-potential similar to the coarse emulsion, for all pressures and number of cycles applied. These data corroborate with what is described in literature, in which the increase in operating pressure has been reported as being directly proportional to the decrease in average droplet size; the number of cycles is related to this reduction until it reaches a plateau (Qian and McClements 2011; Salvia-Trujillo et al. 2013; Yang and McClements 2013). In contrast, Qian and McClements (2011) reported that higher working pressures and number of cycles $\left(13.8 \times 10^{7} \mathrm{~Pa} ; 10\right.$ and 20 cycles $)$ resulted in slightly larger droplet sizes; Jafari et al. (2008) attributed this phenomenon, initially, to an increase in droplet collision and recoalescence.

Conditions chosen as optimum were $10.3 \times 10^{7} \mathrm{~Pa}$, in order to avoid excessive energy to the system as $13.8 \times 10^{7} \mathrm{~Pa}$, for example, with 10 cycles, because, although 5 cycles resulted in satisfactory nanoemulsions, the presence of a second population $(1.2 \%)$ of larger droplets was described; when using 10 cycles, this population was not observed (Fig. 2). The optimal number of cycles consequently results in lower size distribution and prevents instabilities such as Ostwald ripening (Lee and Norton 2013).

\section{Characterization of Pepper Extract Nanoemulsions}

Based on the preliminary tests, the optimum pepper extract nanoemulsion ( $2 \% \mathrm{w} / \mathrm{w}$ pepper extract, $97 \% \mathrm{w} / \mathrm{w}$ Milli-Q® water and $1 \% w / w$ mixture of Span $80 \circledR$ and Tween $\circledast 80$ ) was produced at $10.3 \times 10^{7} \mathrm{~Pa}$ with 10 cycles and, afterward, submitted to physical and morphological characterization, followed by stability tests.

\section{Color}

Values of $\mathrm{L}^{*}, \mathrm{a}^{*}$, and $\mathrm{b}^{*}$ color parameters and whiteness index (\%) were $70.00 \pm 0.004,-2.20 \pm 0.01,0.71 \pm 0.01$, and $59.90 \pm 0.02$, respectively. The $\mathrm{L}^{*}$ value indicates lightness and tendency to dark, not transparency; negative $\mathrm{a}^{*}$ and positive $b^{*}$ values indicate little tendency to green and yellow, respectively. Both $\mathrm{a}^{*}$ and $\mathrm{b}^{*}$ are near zero, which indicates that the predominant color is neutral (Takasui 2011); this can be confirmed by high whiteness index. The expected color in the present study was white, as it tends to grow stronger with increased contrast in refractive index, caused by high concentration of droplets and the presence of droplets larger than $40 \mathrm{~nm}$ (McClements 2002; McClements 2012; SalviaTrujillo et al. 2013).
Table 2 Effect of soybean oil and surfactant concentrations on average droplet size and polydispersity of soybean oil coarse emulsion prepared by high-speed homogenizer at a combination of time and gradual increasing speed

\begin{tabular}{lllll}
\hline $\begin{array}{l}\text { Soybean oil } \\
(\mathrm{g} / 100 \mathrm{~g})\end{array}$ & $\begin{array}{l}\text { Surfactant } \\
(\mathrm{g} / 100 \mathrm{~g})\end{array}$ & $\begin{array}{l}\text { Water } \\
(\mathrm{g} / 100 \mathrm{~g})\end{array}$ & $\begin{array}{l}\text { Average droplet size } \\
(\mathrm{nm})\end{array}$ & Polydispersity \\
\hline 7.5 & 2.5 & 90 & $918 \pm 67^{\mathrm{A}}$ & $0.399 \pm 0.014^{\mathrm{a}}$ \\
5 & 2.5 & 92.5 & $334 \pm 10^{\mathrm{D}}$ & $0.316 \pm 0.090^{\mathrm{bc}}$ \\
2.5 & 2.5 & 95 & $213 \pm 2^{\mathrm{E}}$ & $0.165 \pm 0.018^{\mathrm{d}}$ \\
5 & 1.5 & 93.5 & $426 \pm 23^{\mathrm{BC}}$ & $0.323 \pm 0.011^{\mathrm{b}}$ \\
2.5 & 1 & 96.5 & $386 \pm 8^{\mathrm{CD}}$ & $0.270 \pm 0.008^{\mathrm{c}}$ \\
1.25 & 0.5 & 98.25 & $451 \pm 29^{\mathrm{B}}$ & $0.341 \pm 0.009^{\mathrm{b}}$ \\
\hline
\end{tabular}

Equal letters indicate no significant difference $(p>0.05)$ between samples in the same column 
Table 3 Effect of working pressure and number of cycles at average droplet size of pepper extract nanoemulsion (97:2:1\% $w / w$ of aqueous phase, lipid phase, and surfactant concentrations, respectively) produced by high-pressure homogenization

\begin{tabular}{lclc}
\hline Working pressure $(\mathrm{Pa})$ & Number of cycles & Average droplet size $(\mathrm{nm})$ & Polydispersity \\
\hline $6.9 \times 10^{7}$ & 5 & $139 \pm 1^{\mathrm{A}}$ & $0.098 \pm 0.015^{\mathrm{a}}$ \\
$6.9 \times 10^{7}$ & 10 & $141 \pm 1^{\mathrm{A}}$ & $0.097 \pm 0.013^{\mathrm{a}}$ \\
$6.9 \times 10^{7}$ & 20 & $145 \pm 2^{\mathrm{B}}$ & $0.181 \pm 0.018^{\mathrm{b}}$ \\
$10.3 \times 10^{7}$ & 5 & $132 \pm 1^{\mathrm{C}}$ & $0.102 \pm 0.012^{\mathrm{a}}$ \\
$10.3 \times 10^{7}$ & 10 & $134 \pm 2^{\mathrm{C}}$ & $0.102 \pm 0.012^{\mathrm{a}}$ \\
$10.3 \times 10^{7}$ & 20 & $140 \pm 1^{\mathrm{A}}$ & $0.095 \pm 0.010^{\mathrm{a}}$ \\
$13.8 \times 10^{7}$ & 5 & $132 \pm 1^{\mathrm{C}}$ & $0.099 \pm 0.003^{\mathrm{a}}$ \\
$13.8 \times 10^{7}$ & 10 & $139 \pm 1^{\mathrm{A}}$ & $0.262 \pm 0.008^{\mathrm{c}}$ \\
$13.8 \times 10^{7}$ & 20 & $138 \pm 1^{\mathrm{A}}$ & $0.101 \pm 0.024$ \\
\hline
\end{tabular}

Equal letters indicate no significant difference $(p>0.05)$ between samples in the same column

\section{Atomic Force Microcopy and Cryo-scanning Electron Microscopy}

In micrographs of AFM, it is possible to observe droplets with undefined shapes (Fig. 3). Preetz et al. (2010) and SalviaTrujillo et al. (2013) suggested that sample preparation or weak adsorption of droplets on the surface of a substrate can be the cause of deformed droplets. On another hand, CSEM is an advanced technique that allows the observation of colloidal systems, such as nanoemulsions, in their natural form (Klang et al. 2012; Mikula and Munoz 2000). In CSEM micrographs of pepper nanoemulsions, the presence of clear spherical droplets with sufficient uniformity may be observed, revealing droplets of the oil phase surrounded by the aqueous phase (Fig. 4). The presence of larger and smaller droplets in minor proportions can be described in different areas of the sample, which is common with nanoemulsions, particularly in undiluted samples (Saupe et al. 2006).

\section{Environmental Stress_Centrifugal and Thermal Stresses}

The variables analyzed in order to investigate the stability were droplet size, size distribution, and $\zeta$-potential. Besides those, nanoemulsions were observed by naked eye. Samples of the optimum pepper nanoemulsion did not change macroscopically (visually), or show creaming or phase separation, after the following tests: centrifugal stress, heating/cooling cycling stability, and temperature ramp, maintaining their original aspect. Regarding thermal processing stability, nanoemulsions submitted to 70 and $90{ }^{\circ} \mathrm{C}$ showed bigger droplets than the positive control on the seventh day (Table 4). Small changes in average droplet size can occur without significantly destabilizing the system, especially at high temperatures. Also, PDI values remained below 0.2, suggesting that the system is uniform and stable (mono-dispersed), and, for this reason, storage stability testing was considered a viable next step (Preetz et al. 2010).

Freeze-thaw cycling stability was characterized to predict the effect of freezing and thawing of food matrixes or packages containing pepper extract nanoemulsions, subjected to the freezing process, in order to ensure stability during final consumption and simulate cold chain problems. Phase separation of the optimum pepper extract nanoemulsion occurred after the third cycle (Fig. 5), in which the average droplet size varied between 0.3 and $0.5 \mu \mathrm{m}$, exceeding $1.0 \mu \mathrm{m}$ after the second cycle, and the $\zeta$-potential ranged from 20 to $30 \mathrm{mV}$. Surface droplets presents a negative electrical charge with nonionic surfactants and values more negatives than - 30 are considered ideal to keep emulsions stable, because equal negative charges will cause the droplets to repel each other, avoiding aggregation and destabilization ( $\mathrm{Hsu}$ and $\mathrm{Nacu}$ 2003). Considering that negative charge of $\zeta$-potential reduced from -30 to -20 , it can be suggested the destabilization occurred, these instabilities can be a result of slow freezing in addition to the high amount of water, forming crystals around the droplets, which break while thawing. Aoki et al.
Fig. 2 Size distribution curve of optimum pepper extract nanoemulsion $(2 \% w / w$ pepper extract, $97 \% w / w$ Milli-Q ${ }^{\circledR}$ water and $1 \% \mathrm{w} / \mathrm{w}$ mixture of $\operatorname{Span} 80 \circledR$ and Tween ${ }^{\circledR} 80$ )

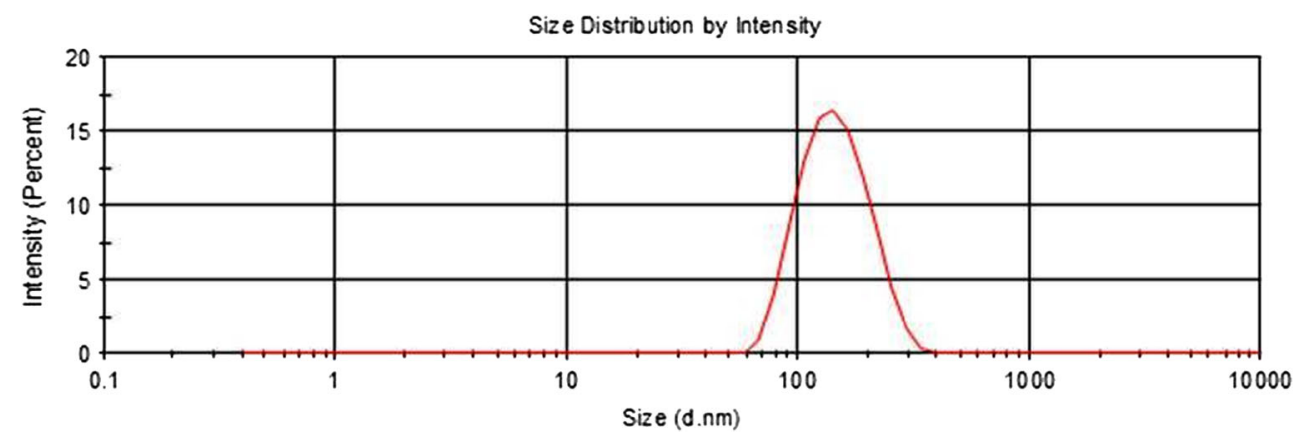


Fig. 3 Two (a) and three (b) dimensional atomic force micrographs of optimum pepper extract nanoemulsion (2\%wt pepper extract, $97 \%$ wt Milli-Q® water and $1 \%$ wt mixture of Span $80 ®$ and Tween $® 80$ ) a

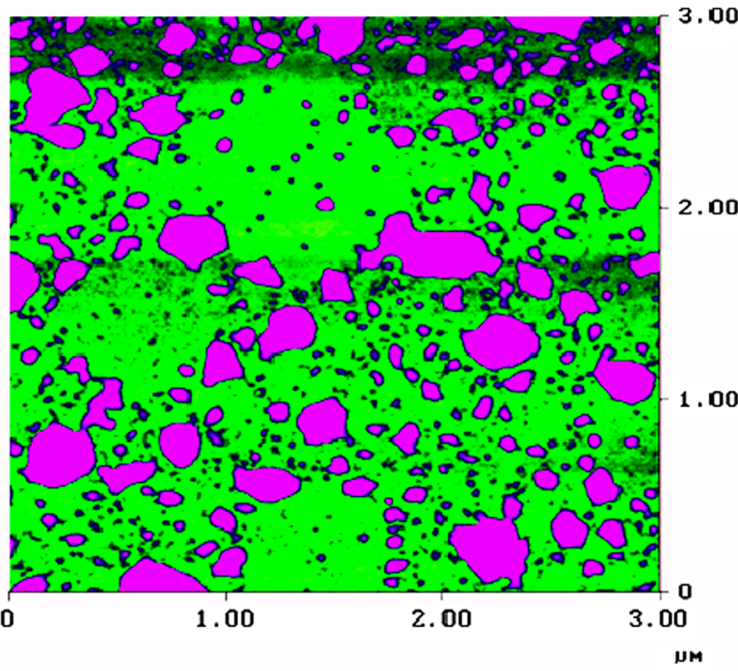

3.00

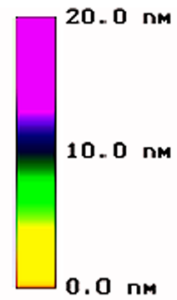

Djtita] Instruments NanoScope Scan size $3.000 \mathrm{jm}$ Scan rate $1.001 \mathrm{~Hz}$ Injue Diata Hei ght Data scale $20.00 \mathrm{~nm}$

b

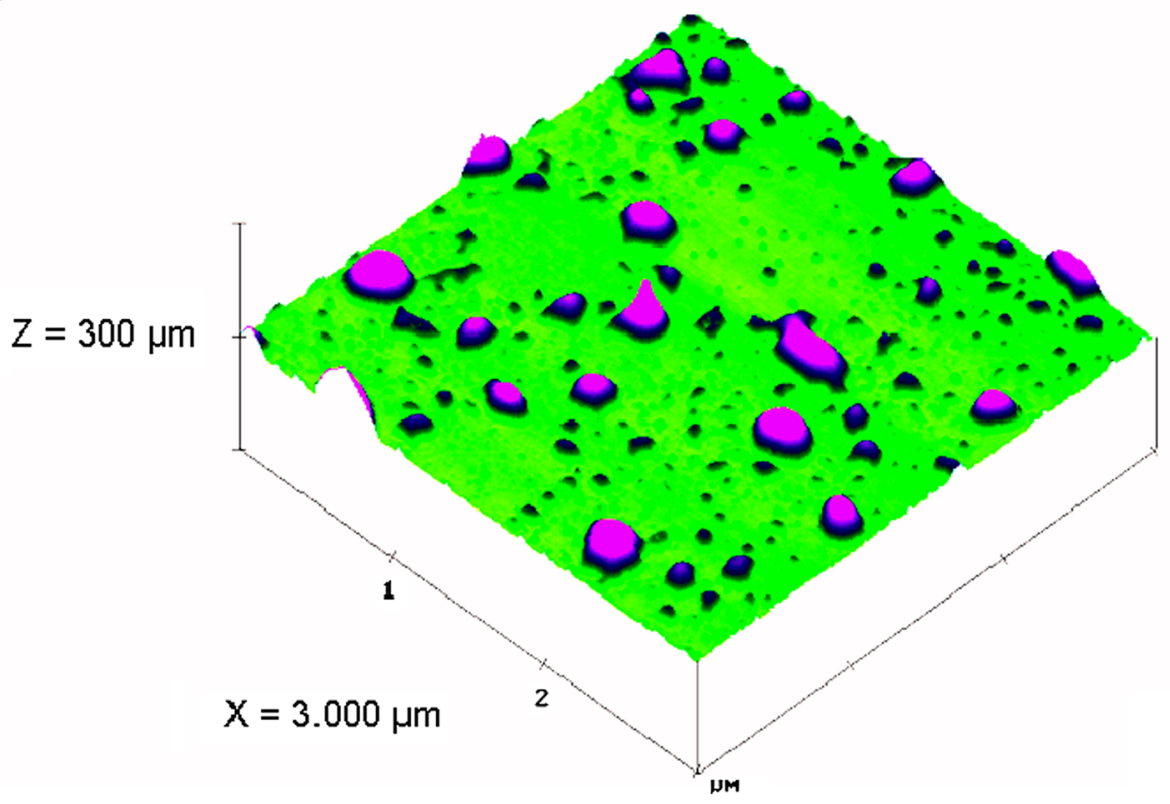

Fig. 4 Cryo-scanning electron micrographs of optimum pepper extract nanoemulsion $((2 \% w / w$ pepper extract, $97 \%$ w/w Milli$\mathrm{Q}{ }^{\circledR}$ water and $1 \% w / w$ mixture of Span $80 \circledR$ and Tween $® 80)$ ) at $700 \mathrm{~nm}(\mathbf{a})$ and $1 \mu \mathrm{m}(\mathbf{b})$ resolution
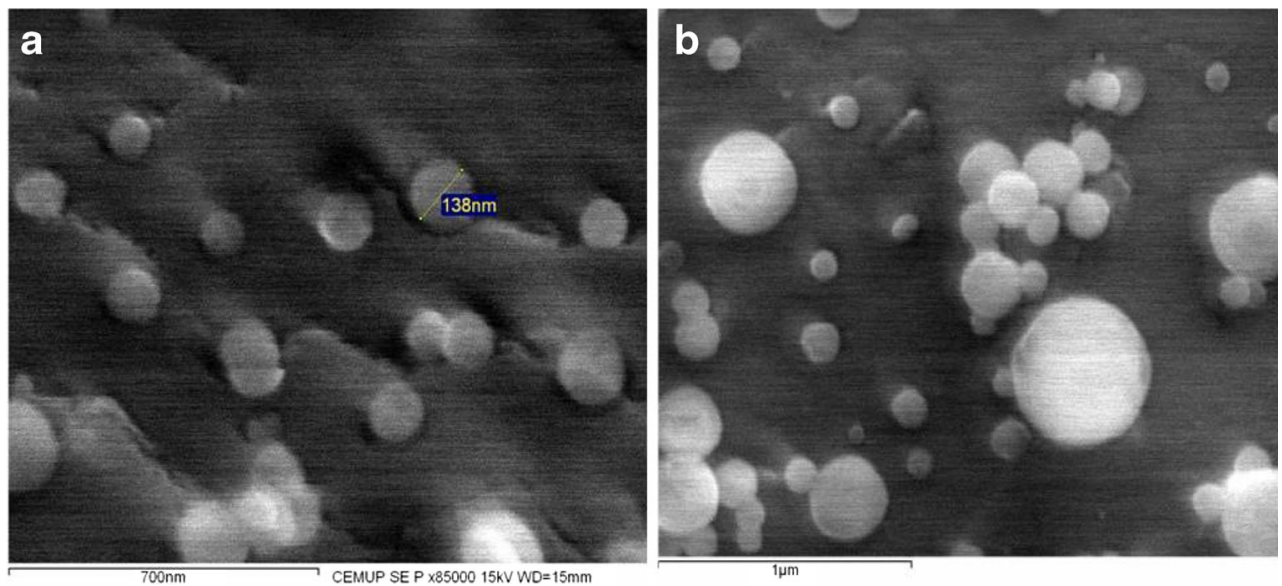
Table 4 Average droplet size of pepper nanoemulsions $(97: 2: 1 \%$ $w / w$ of aqueous phase, lipid phase, and surfactant concentrations, respectively) produced by high-pressure homogenization (at $10.3 \times 10^{7} \mathrm{~Pa}$ and 10 cycles) submitted to environmental stability tests

\begin{tabular}{llll}
\hline Treatments & Average droplet size $(\mathrm{nm})$ & Polydispersity & Zeta potential $(\mathrm{mV})$ \\
\hline Positive control & $142 \pm 1$ & $0.090 \pm 0.001$ & $-36.00 \pm 1.00$ \\
Thermal processing stability & & & \\
Water bath $70^{\circ} \mathrm{C}$ & $139 \pm 1$ & $0.105 \pm 0.003$ & $-37.01 \pm 3.90$ \\
Water bath $70^{\circ} \mathrm{C}($ day 7$)$ & $146^{*} \pm 1$ & $0.108 \pm 0.001$ & $-36.57 \pm 2.58$ \\
Water bath $90^{\circ} \mathrm{C}$ & $138 \pm 1$ & $0.119 \pm 0.032$ & $-36.93 \pm 1.78$ \\
Water bath $90^{\circ} \mathrm{C}$ (day 7$)$ & $146^{*} \pm 1$ & $0.142 \pm 0.038$ & $-36.80 \pm 2.97$ \\
Heating/cooling cycling stability & & & \\
Cycle 1 & $142 \pm 1$ & $0.107 \pm 0.003$ & $-36.50 \pm 3.92$ \\
Cycle 2 & $140 \pm 1$ & $0.105 \pm 0.001$ & $-36.45 \pm 2.33$ \\
Cycle 3 & $144 \pm 1$ & $0.097 \pm 0.009$ & $-36.50 \pm 0.707$ \\
Cycle 4 & $142 \pm 1$ & $0.108 \pm 0.030$ & $-35.65 \pm 0.354$ \\
Cycle 5 & $140 \pm 2$ & $0.102 \pm 0.030$ & $-37.45 \pm 3.75$ \\
Cycle 6 & $145^{*} \pm 1$ & $0.122 \pm 0.283$ & $-38.45 \pm 0.354$ \\
Temperature ramp & & & \\
From -10 to $80{ }^{\circ} \mathrm{C}$ & $138 \pm 1$ & $0.112 \pm 0.010$ & $-37.56 \pm 0.981$ \\
Centrifugal stress & & & $-36.87 \pm 2.73$ \\
$80 \mathrm{~g}$ & $144 \pm 1$ & $0.091 \pm 0.004$ & $-34.50 \pm 7.30$ \\
$250 \mathrm{~g}$ & $138 \pm 1$ & $0.096 \pm 0.006$ & $-38.03 \pm 3.37$ \\
$1000 \mathrm{~g}$ & $143 \pm 1$ & $0.108 \pm 0.013$ & \\
$3050 \mathrm{~g}$ & $142 \pm 1$ & $0.107 \pm 0.008$ & $-33 \pm 0.709$ \\
\hline
\end{tabular}

*Significant difference $(p<0.05)$ compared to positive control in the same column
(2005) alerted that during this specific analysis, it is necessary to be careful when interpreting DLS measurements; Donsi et al. (2011) observed the same phenomenon working with lecithin emulsions. Coalescence and possibly high flocculation index, caused by destabilization of droplets, interfere directly in the light scattering of the device, explaining the broad and inconstant range of droplet sizes and $\zeta$-potential. Freezing processes can cause a lot of physical and chemical alterations to food, and in colloidal systems, the crystallization of surfactants may also occur, leading to droplet breakage during

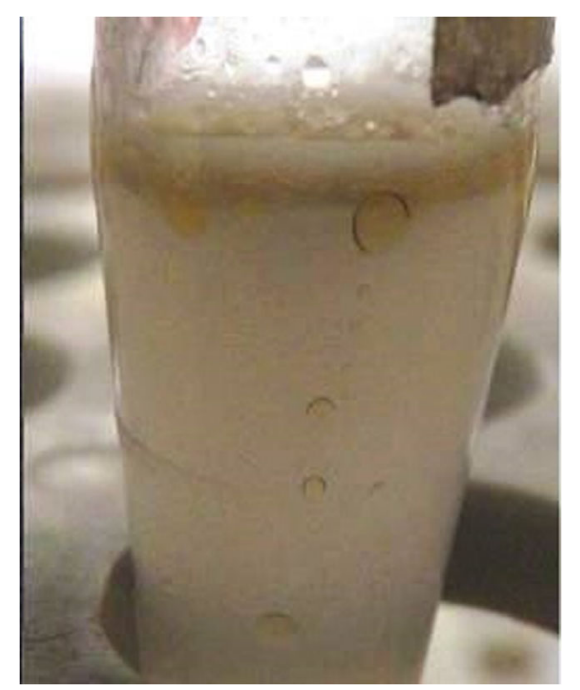

Fig. 5 Pepper extract nanoemulsion after three freeze-thaw cycles thawing (Aoki et al. 2005; Mun et al. 2013). Stability of the pepper nanoemulsion was maintained for two cycles, which can be considered a positive result concerning food matrixes since it is ideal to not re-freeze food.

\section{Storage Stability}

It is also important to study the nanoemulsion stability under storage conditions. This is necessary to determine its shelf life in a physical-chemical point of view. The optimum pepper extract nanoemulsion showed signs of instability only when at $37^{\circ} \mathrm{C}$, after more than 60 days $(p<0.05)$. Regarding all the other storage conditions, no significant difference $(p>0.05)$ was observed in average droplet size (Table 5) among the samples and the positive control over 120 days, evidencing the nanoemulsion's stability; $\zeta$-potential and polydispersity remained with no difference to control $(p>0.05)$. The primary mechanism of instability of these compounds is Ostwald ripening, which occurs due to the solubility of the dispersed phase in the continuous phase, making small droplets smaller by supplying large droplets, and, in turn, making the latter larger. The Ostwald ripening rate may be calculated by using linear regression of the cube of the droplet radius $(R)$ versus time, in which when the $r^{2}$ value is larger than 0.8 , it indicates that Ostwald ripening is responsible for destabilization (Bernardi et al. 2011). The $r^{2}$ value of the pepper extract nanoemulsion, stored at $37{ }^{\circ} \mathrm{C}$, was 0.41 , ruling out the 
Table 5 Storage stability of pepper extract nanoemulsion (97:2:1\% $w / w$ of aqueous phase, lipid phase, and surfactant concentrations, respectively, obtained at $10.3 \times 10^{7} \mathrm{~Pa}$ and 10 cycles) under different storage temperature conditions

\begin{tabular}{|c|c|c|c|c|c|c|c|}
\hline \multirow[b]{3}{*}{$\mathrm{T}\left({ }^{\circ} \mathrm{C}\right)$} & \multicolumn{7}{|c|}{ Average droplet size (nm) } \\
\hline & \multicolumn{7}{|l|}{ Time (day) } \\
\hline & 0 & 7 & 15 & 30 & 60 & 90 & 120 \\
\hline 4 & $139 \pm 2^{\mathrm{Aa}}$ & $143 \pm 1^{\mathrm{Aa}}$ & $142 \pm 1^{\mathrm{Aa}}$ & $142 \pm 1^{\mathrm{Aa}}$ & $142 \pm 0^{\mathrm{Aa}}$ & $140 \pm 2^{\mathrm{Aa}}$ & $138 \pm 2^{\mathrm{Aa}}$ \\
\hline 25 & & $144 \pm 1^{\mathrm{Aa}}$ & $140 \pm 1^{\mathrm{Aa}}$ & $142 \pm 1^{\mathrm{Aa}}$ & $141 \pm 2^{\mathrm{Aa}}$ & $142 \pm 2^{\mathrm{Aa}}$ & $142 \pm 1^{\mathrm{Aa}}$ \\
\hline 37 & & $141 \pm 0^{\mathrm{Aa}}$ & $141 \pm 1^{\mathrm{Aa}}$ & $145 \pm 1^{\mathrm{Aa}}$ & $178 \pm 2^{\mathrm{Bb}}$ & $291 \pm 4^{\mathrm{Cc}}$ & $291 \pm 13^{\mathrm{Dd}}$ \\
\hline
\end{tabular}

Equal uppercase letters indicate no significant difference $(p>0.05)$ between samples of the same nanoemulsion by column; equal lowercase letters indicate no significant difference between samples of the same nanoemulsion by line possibility of instability by Ostwald ripening. Other possible mechanisms that could be responsible for increasing average droplet size are flocculation and coalescence. The presence of two or more initial populations of droplets is a consequence of formulation, but the formation of these populations over time is related to the destabilization process.

Boyd et al. (1972) observed the influence of storage temperatures at 5,25 , and $40{ }^{\circ} \mathrm{C}$, and concluded that this parameter exerts minor influence when compared to HLB dependency in coalescence; however, at $40{ }^{\circ} \mathrm{C}$, the emulsion coalesced after 15 days, probably due to water loss, which promotes connections between groups of ethylene oxide and polyoxyethylene adjacent groups. When storage is carried out at temperatures close to those of production, water loss may occur, in addition to dehydration of hydrophilic nonionic surfactants. Bernardi et al. (2011) conducted tests on $\mathrm{O} / \mathrm{W}$ nanoemulsions, containing rice oil as the oil phase, and different combinations of Tween ${ }^{\circledR}$ and Span ${ }^{\circledR}$ as surfactants, in order to achieve an HLB value of 8.0. The authors then compared a low energy process with a high energy process, and observed that regardless of the storage conditions, all formulations prepared by high-pressure homogenization destabilized after 30 days. Conversely, in the present study, the stability observed for nanoemulsions stored at room temperature indicates that the production method was satisfactory, as was the formulation process; however, increasing the temperature will lead to faster chemical reactions, explaining instability at $37^{\circ} \mathrm{C}$.

\section{Conclusions}

Pepper nanoemulsions were developed, with average droplet sizes varying between $132 \pm 1.0$ and $145 \pm 2.0 \mathrm{~nm}$, polydispersity inferior to 0.15 , and $\zeta$-potential of $-36.71 \mathrm{mV}$. The process conditions influenced the final droplet size and stability of the nanoemulsion. The ideal surfactant/oil ratio was 1:2 (in weight), which, together with a gradual increase of homogenization speed, enabled significant reductions in droplet size before passing the coarse emulsion through the high-pressure homogenizer. Nanosized droplets were spherical, homogeneous, and was stable when submitted to almost all environmental stresses. Pepper nanoemulsion was stable during storage at room temperature over 120 days.

The pepper nanoemulsion studied in this work can be considered as an interesting prospect for application in the food industry because its physico-chemical characteristics and stability; however, it is clear that each step of development may influence the formation of different systems of the same formulation. More studies are necessary to fully elucidate the underlying mechanisms.

Acknowledgements The first author gratefully acknowledges the CNPq and CAPES (National Council for Scientific and Technological Development, Program Science without Boarder) for the "SWE" $\mathrm{PhD}$ (Process 236877/2012-1) fellowship, and CAPES for the national PhD fellowship. The last author acknowledges the São Paulo Research Foundation (FAPESP) Brazil, for the grant (CEPID-FoRC, 2013/07914-8).

\section{References}

Anarjan, N., Mirhousseini, H., Baharin, B. S., \& Lupton, C. P. (2010). Effect of processing conditions on physicochemical properties of astaxanthin nanodispersions. Food Chemistry, 123(2), 477-483. https://doi.org/10.1016/j.foodchem.2010.05.036.

Anton, N., \& Vandamme, T. F. (2011). Nano-emulsions and micro-emulsions: clarifications of the critical differences. Pharmaceutical Research, 28, 978-985. https://doi.org/10.1007/s11095-010-03091.

Aoki, T., Decker, E. A., \& McClements, D. J. (2005). Influence of environmental stresses on stability of $\mathrm{O} / \mathrm{W}$ emulsions containing droplets stabilized by multilayered membranes produced by a layer-by-layer electrostatic deposition technique. Food Hydrocolloids, 19(2), 209220. https://doi.org/10.1016/j.foodhyd.2004.05.006.

Bernardi, D. S., Pereira, T. A., Maciel, N. R., Bortoloto, J., Vieira, G. S., Oliveira, G. C., et al. (2011). Formation and stability of oil-in-water nanoemulsions containing rice bran oil: in vitro and in vivo assessments. Journal of Nanobiotechnology, 9(44), 1-9. https://doi.org/ 10.1186/1477-3155-9-44.

Boyd, J., Parkinson, C., \& Sherman, P. (1972). Factors affecting emulsion stability and the HLB concept. Journal of Colloid and Interface Science, 41(2), 359-370. https://doi.org/10.1016/0021-9797(72) 90122-1. 
Cheong, J. N., Tan, C. P., Man, Y. B. C., \& Misran, M. (2008). $\alpha$ Tocopherol nanodispersions: preparation, characterization and stability evaluation. Journal of Food Engineering, 89(2), 204-209. https://doi.org/10.1016/j.jfoodeng.2008.04.018.

Choi, A. J., Kim, C. J., Cho, Y. J., Hwang, J. K., \& Kim, C. (2009). Effects of surfactants on the formation and stability of capsaicinloaded nanoemulsions. Food Science and Biotechnology, Korea, 18(5), 1161-1172.

Costa, L. M., Moura, N. F., Marangoni, C., Mendes, C. E., \& Teixeira, A. O. (2009). Atividade antioxidante de pimentas do gênero Capsicum. Ciência e Tecnologia de Alimentos, 30(1), 51-59. https://doi.org/10. 1590/S0101-20612009005000004.

Donsi, F., Wang, Y. \& Huang, Q. (2011). Freeze-thaw stability of lecithin and modified starch-based nanoemulsions. 25, 1327-1336.doi: https://doi.org/10.1016/j.foodhyd.2010.12.008.

Ernandes, F. M. P. G., \& Garcia-Cruz, C. H. (2007). Atividade antimicrobiana de diversos óleos essenciais em microrganismos isolados do meio ambiente. Boletim do Centro de Pesquisa de Processamento de Alimentos, 25(2), 193-206. https://doi.org/10. 5380/cep.v25i2.9754.

Gullapali, R. P., \& Sheth, B. B. (1999). Influence of an optimized nonionic emulsifier blend on properties of oil-in-water emulsions. European Journal of Pharmaceutics and Biopharmaceutics, 48, 233-238. https://doi.org/10.1016/S0939-6411(99)00048-X.

Guojun, L. V., Fumin, W., Cai, W., \& Zhan, X. (2014). Characterization of the addition of lipophilic Span 80 to the gydrophilic Tween 80stabilized emulsions. Colloids and Surfaces A: Physicochemical Engineering Aspects, 447, 8-13. https://doi.org/10.1016/j.colsurfa. 2014.01.066.

Hsu, Q., \& Nacu, A. (2003). Behavior of soybean oil-in-water emulsion stabilized by nonionic surfactant. Journal of Colloids and Interface Sciences, 259, 374-381. https://doi.org/10.1016/S0021-9797(02) 00207-2.

Huang, Q., Yu, H., \& Ru, Q. (2009). Bioavailability and delivery of nutraceuticals using nanotechnology. Journal of Food Science, 75(1), 50-57. https://doi.org/10.1111/j.1750-3841.2009.01457.x.

Hung, Y., Kok, T. M., \& Verbeke, W. (2016). Consumer attitude and purchase intention towards processed meat products with natural compounds and a reduced level of nitrite. Meat Science, 121, 119126. https://doi.org/10.1016/j.meatsci.2016.06.002.

Jafari, S. M., Assadpoor, E., He, Y., \& Bhandari, B. (2008). Recoalescence of emulsion droplets during high-energy emulsification. Food Hydrocolloids, 22, 1191-1202. https://doi.org/10.1016/j. foodhyd.2007.09.006.

Kentish, S., Wooster, T. J., Ashokkumar, S., Balachandran, R., Mawson, R., \& Simons, L. (2008). The use of ultrasonics for nanoemulsion preparation. Innovative Food Science and Emerging Technologies, 9(2), 170-175. https://doi.org/10.1016/j.ifset.2007.07.005.

Klang, V., Matsko, N. B., Valenta, C., \& Hofer, F. (2012). Electron microscopy of nanoemulsions: an essential tool for characterisation and stability assessment. Micron, 43(2-3), 85-103. https://doi.org/ 10.1016/j.micron.2011.07.014.

Lee, S. J., \& McClements, D. J. (2010). Fabrication of protein-stabilized nanoemulsions using a combined homogenization and amphiphilic solvent dissolution/evaporation approach. Food Hydrocolloids, 24(6-7), 560-569. https://doi.org/10.1016/j.foodhyd.2010.02.002.

Lee, L., \& Norton, I. T. (2013). Comparing droplet break-up for a highpressure valve homogenizer and a microfluidizer for the potential production of food-grade nanoemulsions. Journal of Food Engineering, 114(2), 158-163. https://doi.org/10.1016/j.jfoodeng. 2012.08.009

Martillanes, S., Rocha-Pimienta, J.; Cabrera-Bañegil, M; MartínVertedor, D. \& Delgado-Adámez, J. (2017). Application of phenolic compounds for food preservation: food additive and active packaging. In: Prof. Marcos Soto-Hernández (Ed.) Phenolic Compounds Biological Activity. InTech, doi:https://doi.org/10.5772/66885.
Mason, T. G., Wilking, J. N., Meseson, K., Chang, C. B., \& Graves, S. M. (2006). Nanoemulsions: formation, structure, and physical properties. Journal of Physics: Condensed Matter, 18(41), 635-666. https://doi.org/10.1088/0953-8984/18/41/R01.

Matsaridou, I., Panagiotis, B., Salis, A., \& Nikolakakis, I. (2012). The influence of surfactant HLB and oil/surfactant ratio on the formation and properties of self-emulsifying pellets and microemulsion reconstitution. AAPS PharmSciTech, 13(4), 1319-1330. https://doi.org/ 10.1208/s12249-012-9855-7.

McClements, D. J. (2002). Colloidal basis of emulsion color. Current Opinion in Colloid and Interface Science, 7, 451-455. https://doi. org/10.1016/S1359-0294(02)00075-4.

McClements, D. J. (2012). Nanoemulsions versus microemulsions: terminology, differences, and similarities. Soft Matter, 8, 1719-1729. https://doi.org/10.1039/C2SM06903B.

Mikula, R. J., \& Munoz, V. A. (2000). Characterization of emulsions and suspensions in the petroleum industry using cryo-SEM and CLSM. Colloid and Surfaces A: Physicochemical and Engineering Aspects, 174(1-2), 23-36. https://doi.org/10.1016/S0927-7757(00)00518-5.

Mun, S., Choi, Y., Park, K. H., Shim, J. Y., \& Kim, Y. R. (2013). Influence of environmental stresses on the stability of W/O/W emulsions containing enzymatically modified starch. Carbohydrate Polymers, 92(2), 1503-1511.

Nazarzadeh, E., Anthonypillai, T., \& Sajjadi, S. (2013). On the growth mechanisms of nanoemulsions. Journal of Colloids and Interface Science, 397, 154-162. https://doi.org/10.1016/j.carbpol.2012.10. 050 .

Persson, K., Blute, I. A., Mira, I. C., \& Gustafsson, J. (2014). Creation of well-defined particle stabilized oil-in-water nanoemulsions. Colloids and Surfaces A: Physicochemical and Engineering Aspects, 459, 48-57. https://doi.org/10.1016/j.colsurfa.2014.06. 034.

Preetz, C., Hauser, A., Hause, G., Kramer, A., \& Mader, K. (2010). Application of atomic force microscopy and ultrasonic resonator technology on nanoscale: distinction of nanoemulsions from nanocapsules. European Journal of Pharmaceutical Sciences, 39(1-3), 141-151. https://doi.org/10.1016/j.ejps.2009.11.009.

Prista, L. N., Alves, A. C., \& Morgado, R. (1992). Técnica farmacêutica e farmácia galênica (4th ed.). Lisboa: Fundação Calouste Gulbenkian.

Qian, C., \& McClements, D. J. (2011). Formation of nanoemulsion stabilized by model food-grade emulsifiers using high-pressure homogenization: factors affecting average droplet size. Food Hydrocolloids, 25(5), 1000-1008. https://doi.org/10.1016/j. foodhyd.2010.09.017.

Rao, J., \& McClements, D. J. (2012). Lemon oil solubilization in mixed surfactant solutions: rationalizing microemulsion and nanoemulsion formation. Food Hydrocolloids, 26(1), 268-276. https://doi.org/10. 1016/j.foodhyd.2011.06.002.

Reyes-Escogido, M. L., Gonzalez-Mondragon, E. G., \& VazquezTzompantzi, E. (2011). Chemical and pharmacological aspects of capsaicin. Molecules, 16, 1253-1270. https://doi.org/10.3390/ molecules 16021253

Salvia-Trujillo, L., Rojas-Grau, M. A., Soliva-Fortuny, R., \& MartínBelloso, O. (2013). Effect of processing parameters on physicochemical characteristics of microfluidized lemongrass essential oilalginate nanoemulsions. Food Hydrocolloids, 30(1), 401-407. https://doi.org/10.1016/j.foodhyd.2012.07.004.

Saranya, S., Chansrasekaran, N., \& Mukherjee, A. (2012). Antibacterial activity of eucalyptus oil nanoemulsion against Proteus Mirabilis. International Journal of Pharmacy and Pharmaceutical Sciences, 4(3), 668-671.

Saupe, A., Gordon, K. C., \& Rades, T. (2006). Structural investigations on nanoemulsions, solid lipid nanoparticles and nanostructured lipid carriers by cryo-field emission scanning electron microscopy and Raman spectroscopy. International Journal od Pharmaceutics, 
Amsterdan, 314(1), 56-62. https://doi.org/10.1016/j.ijpharm.2006. 01.022 .

Schmidts, T., Dobler, D., Nissing, C., \& Runkel, F. (2009). Influence of hydrophilic surfactants on the properties of multiple W/O/W emulsions. Journal of Colloid and Interface Science, 338(1), 184-192. https://doi.org/10.1016/j.jcis.2009.06.033.

Shantilal, J., \& Bhattacharya, S. (2014). Nanoparticles and nanotechnology in food, in conventional and advanced food processing technologies. Chichester, UK: John Wiley and Sons Ltd. https://doi.org/10. 1002/9781118406281.ch23.

Silva, F.J.F. et al. (2009). Determinação do potencial antioxidante do extrato filtrado de Capsicum baccatum (pimenta dedo-de-moça) através do método DPPH. In: SALÃO DE INICIAÇÃ̃O CIENTÍFICA - PUCRS, 10.; Porto Alegre. Anais.

Silva, H. D., Cerqueira, M. A., Souza, B. W. S., Ribeiro, C., Avides, M. C., Quintas, M., et al. (2011). Nanoemulsions of b-carotene using high-energy emulsification-evaporation technique. Journal of Food Engineering, 102(2), 130-135. https://doi.org/10.1016/j.jfoodeng. 2010.08.005.

Silva, H. D., Cerqueira, M. A., \& Vicente, A. A. (2012). Nanoemulsions for food applications: development and characterization. Food Bioprocess Technology, 5(3), 854-867. https://doi.org/10.1007/ s11947-011-0683-7.

Sivakumar, M., Tang, S. Y., \& Tan, K. W. (2014). Cavitation technology - a greener processing technique for the generation of pharmaceutical nanoemulsions. Ultrasonics Sonochemistry, 21(6), 20692083. https://doi.org/10.1016/j.ultsonch.2014.03.025.

Sricharoen, P., Lamaiphan, N., Patthawaro, P., Limchoowong, N., Techawongstien, S., et al. (2016). Phytochemicals in capsicum oleoresin from different varieties of hot chili peppers with their antidiabetic and antioxidant activities due to some phenolic compounds. Ultrasonics Sonochemistry, 38, 629-639. https://doi.org/ 10.1016/j.ultsonch.2016.08.018.

Takamura, A., Minow, I., Noro, S., \& Kubo, T. (1979). Effects of Tween and Span group emulsifiers on the stability of $\mathrm{O} / \mathrm{W}$ emulsions. Chemical and Pharmaceutical Bulletin, 27(12), 2921-2926. https://doi.org/10.1248/cpb.27.2921.

Takasui, F. CIE LAB: análise computacional de fotografias. 2011. Ms. Thesis - Faculdade de Odontologia, Universidade Estadual Paulista, Araraquara, 2011. Avaible in: http://www.foar.unesp.br/Home/PosGraduacao/LatoSensu/CienciasOdontologicas/takatsui f me arafo.pdf. Acessed at 2016-07-02.

Vargas, M., Cháfer, M., Albors, A., Chiralt, A., \& González-Martínez, C. (2008). Physicochemical and sensory characteristics of yoghurt produced from mixtures of cows' and goats' milk. International Dairy Journal, 18(12), 1146-1152. https://doi.org/10.1016/j.idairyj.2008. 06.007

Wei, Y., Shuai, L., Guo, D., et al. (2006). Study on antibacterial activity of capsaicin. Food Science, 27(8), 76-78.

Weiss, J., Takhistov, P., \& McClements, D. J. (2006). Functional materials in food nanotechnology. Journal of Food Science, 71(9), 107-116. https://doi.org/10.1111/j.1750-3841.2006.00195.x.

Xing, F., Cheng, G., \& Yi, K. (2006). Study on the antimicrobial activities of the capsaicin microcapsules. Journal of Applied Polymer, 102, 1318-1321. https://doi.org/10.1002/app.23766.

Yang, Y., \& McClements, D. J. (2013). Encapsulation of vitamin E in edible emulsions fabricated using a natural surfactant. Food Hydrocolloids, 30(2), 712-720. https://doi.org/10.1016/j.foodhyd. 2012.09.003. 